\title{
Longitudinal study of a compassion fatigue resiliency intervention in nurse residents
}

\author{
Kathleen Flarity*1,2, Amanda Moorer ${ }^{1}$, Whitney Rhodes Jones ${ }^{2}$ \\ ${ }^{1}$ UCHealth, Aurora, Colorado, United States \\ ${ }^{2}$ University of Colorado, Aurora, Colorado, United States
}

Received: January 21, 2018

Accepted: April 10, 2018

Online Published: April 20, 2018

DOI: $10.5430 /$ jnep.v8n9p61

URL: https://doi.org/10.5430/jnep.v8n9p61

\begin{abstract}
Nurse residents are at greater risk of compassion fatigue compared to more experienced nurses. The amended 2015 Commission on Collegiate Nursing Education Standards of Entry-To-Practice Accreditation of Nurse Residency Programs require that residency programs include approaches to prevent compassion fatigue in their education experiences. This manuscript reports 6-month follow-up results of a longitudinal study in new graduate nurses that evaluated the influence of a four-hour resiliency intervention for compassion fatigue in two hospitals with nurse residency programs within an academic medical center system. We previously reported a statistically significant decrease in mean STS from baseline to 2-months $(p<.001)$. Using a paired $t$-test, compassion satisfaction (CS) and the two elements of compassion fatigue (CF), secondary traumatic stress (STS) and burnout (BO), were measured against 6-month post-intervention. Prevalence and changes in mean scores were reported, suggesting that the results found at 2-month follow-up $(\mathrm{n}=94)$ were sustained at 6-month follow-up $(\mathrm{n}=34)$. The mean STS showed a statistically significant decrease from 2-months and 6-months $(p<.001)$. A decrease in BO and mean increase in CS were not statistically significant, but were trending in a positive direction. As theorized, both STS and BO decreased from baseline to 2-months and 6-months after the-intervention, and CS increased. These results indicate that early compassion fatigue resiliency education may be helpful in increasing CS and lowering the symptoms of CF in nurse residents.
\end{abstract}

Key Words: Compassion fatigue, Resiliency, Nurse residents, Nurse residency program, Burnout, Secondary traumatic stress, Resiliency, Compassion satisfaction, Intervention

\section{INTRODUCTION}

Of all healthcare providers, nurses are the most numerous, perform the most direct care with patients, and routinely bear witness to human suffering. ${ }^{[1]}$ This and other aspects of their profession such as staffing issues, high patient acuity, and unrealistic patient expectations put nurses at risk for compassion fatigue. ${ }^{[2,3]}$ Compassion fatigue has a negative effect on nurses and the institutions they work for. CF has been linked to decreased patient safety, increased employee turnover, increased errors, decreased performance, absenteeism, impaired professionalism, decreased staff and patient satisfaction, and substance abuse. ${ }^{[4-8]}$ Compassion fatigue prevalence among RNs in the United States, ranges from $16 \%$ to $39 \% \cdot{ }^{[6,9]} \mathrm{New}$ graduates account for the highest number of nurses entering the profession. ${ }^{[10]}$ New graduate nurses, the majority of whom are members of the millennial generation, are at higher risk of experiencing compassion fatigue compared to more experienced nurses. ${ }^{[11,12]}$ Over a quarter (28.9\%) of all new graduate nurses leave their jobs within the first year, and more than half or $56.4 \%$ of the

*Correspondence: Kathleen Flarity; Email: Kathleen.Flarity@uchealth.org; Address: UChealth, Aurora, Colorado, United States. 
nurses who left had less than two years of service. ${ }^{[13]}$ In a 2017 AHA workplace resilience survey, millennials (age 18-36) indicated the highest interest (96\%) of any generation in workplace resiliency. ${ }^{[14]}$

The amended 2015 Commission on Collegiate Nursing Education Standards (CCNE) addressing Nurse Residency Program accreditation require nurse residency programs to incorporate strategies to minimize compassion fatigue in their curriculum. ${ }^{[15]}$ Organizational resiliency training has become increasingly imperative to improve employee well-being, health, satisfaction and provide optimal patient care.

\subsection{Background \& operational definitions}

Compassion fatigue $(\mathrm{CF})$ may result from caregivers repeated exposure to patients' and families' misery, pain and from providing sustained empathic care. It can be a causative factor in caregiver burnout. ${ }^{[8,16]} \mathrm{CF}$ leads to emotional, physical, and professional related symptoms that negatively impact patient care and personal and professional relations. ${ }^{[17-19]}$ Compassion fatigue may develop as a result of the work nurse residents perform and may affect their ability to endure in the profession. ${ }^{[3,16,20-22]}$

Due to the significance of CF both personally and professionally, it is theorized that resiliency interventions might offer protective factors to mitigate the negative effects of their work. ${ }^{[16-18,20,23-25]}$ Compassion fatigue is cumulative, it is often not the most horrific patient cared for, it is proving empathetic caring for hundreds of patients. The collective effects of witnessing pain and suffering (secondary trauma) and challenging practice environment may cause nurse residents to experience physical symptoms (e.g. headaches, gastrointestinal issues, sleep disturbances), emotional withdrawal, or empathy blunting. ${ }^{[2,26,27]}$ Compassion fatigue often mirrors post-traumatic stress disorder but is typically more insidious in presentation. Caregivers suffering the most are often unaware they have CF. ${ }^{[1,18]}$ Symptoms and distress are often related to intrusions, avoidance, traumatic memories, rumination, hyperarousal, and exhaustion. ${ }^{[2,3,27,28]}$ Exposure to chronic stress such as nursing may provoke sustained physiological perceived stress arousal and is associated with shortened telomeres (caps at the end of each strand of DNA that protect the chromosomes) and may also affect premature aging. ${ }^{[29,30]}$

\subsection{Definitions}

Compassion satisfaction (CS) is described as the fulfillment and enjoyment one derives from doing their job well and contributing to the well-being of others. ${ }^{[2,3,24,27,31]}$ It is the powerful experience of emotional engagement and compassionate caring of others; despite the cost of caring. ${ }^{[31,32]}$
Resiliency is an individual's resources and strengths (external and internal) which provide the capability to endure, recover and thrive despite life stressors and challenging demands. ${ }^{[14,27,33]}$

Compassion fatigue consists of two components: burnout (BO) and secondary traumatic stress (STS). ${ }^{[16-18,24,31,34]}$

STS refers to the caregiver ill effects from witnessing the pain and suffering of others. STS can be instigated by caring for patients affected by trauma, awareness of the trauma of others, fear, or feelings of professional inadequacy. ${ }^{[2,3,27]}$

Maslach (1976) described a multidimensional model of BO which includes: depersonalization, emotional exhaustion, and diminished personal accomplishment in those in the helping profession. BO has further evolved in health care and is linked with the occupational stressors such as staffing, high patient acuity, work overload, organizational dysfunction, lack of control, unrealistic patient expectations, and lack of organizational and/or leadership support. BO may include feeling hopelessness, exhaustion, depression, frustration, and resentment, causing some nurses to feel that their work does not matter. ${ }^{[2,3,16,18,24,31]}$

\subsection{Synthesis of the evidence}

Although the prevalence of CF in nurses has been well documented, very few studies have been published regarding interventions for CF resiliency, and only one interventional study has been conducted with nurse residents by Flarity, Jones and Reckard, 2016. Their study reported the influence of a resiliency intervention for $\mathrm{CF}$ in graduate nurse residents. The authors found a decrease in mean STS that was statistically significant $(p<.001)$ from the baseline to postintervention and mean BO and mean CS were not statistically significant but trending in a positive direction. The results of their study suggested that $\mathrm{CF}$ resiliency may be favorable to nurse residents in increasing CS and minimizing symptoms of CF in the early stages of their career. The present results are an extension of Flarity et al. (2016), now reporting data from 6-month post-intervention.

Although not conducted in nurse residents, Thimmapuram et al.'s (2017) study on the effect of meditation on telomere length, emotional wellness, and burnout in health care providers found that participants who participated in the 12week meditation had statistically significant improvement in burnout compared to the control group. They also found relative telomere length increased with statistical significance in the younger subset of participants who were in the intervention group. ${ }^{[30]}$ 


\section{METHOD RESEARCH DESIGN}

The study used an intervention-only research design measuring changes in participants over time. This study was conducted at two hospitals with nurse residency programs within an academic medical system, a 500-bed academic medical center and a 448-bed urban hospital in the southwestern United States. Institutional Review Board approval was obtained prior to the study. All nurse residents received a 4-hour CF resiliency intervention with the lead author as part of their yearlong nurse residency program. Those who self-selected to participate in the study provided demographic data and submitted pre-intervention, 2-month and 6-month post-intervention questionnaires. Participants created their own unique identifier for their individual data, in order to maintain confidentiality. Responses were matched using a paired $t$-test at baseline, 2-month and 6-month postintervention. This manuscript reports the 6-month follow-up results, baseline and 2-month results have been previously published. ${ }^{[2]}$

\subsection{Intervention}

The lead author (KF) a certified CF Specialist conducted a four-hour resiliency seminar. The seminar content was modified with permission from Dr. J. Eric Gentry and is described in previous work. ${ }^{[2]}$ Content included: historical perspective of $\mathrm{CF}$, symptoms of $\mathrm{CF}$, negative physiological effects, as well as dynamics of being a novice nurse that may contribute to $\mathrm{CF}$. The interactive seminar included multiple activities; group and individual exercises; videos, didactic lecture and collaborative discussions.

The curriculum included the effects of chronic and prolonged stimulation of the sympathetic nervous system on cognitive function, critical thinking, and behavior, which provided the groundwork for understanding the significance of stress mitigation in $\mathrm{CF}$ resiliency. ${ }^{[35,36]}$

The individual and group activities provided the participants an opportunity to apply the various intervention techniques. Through demonstration and return demonstration of selfregulation skills, the participants were trained on parasympathetic dominance as a technique to reduce the negative impact of stressors. Learning and applying immediate actionable relaxation techniques while in highly stressful situations such as caring for critically ill, injured or in emotionally charged situations helps nurse residents to reduce sympathetic nervous system influence in the moment. The sympathetic nervous system is responsible for the fight or flight response (release of catecholamine, neurotransmitters, and cortisol). The participants also practiced methods of perceptual maturation, self-regulation, and the importance of social connection. These exercises were designed to build critical skills of self-regulation to maintain a calm focus, critical thinking and peak performance during high stress situations, stabilizing the wide bio-chemical swings produced by acutely stressful events. Aside from maintaining mental and physical fitness, there is early evidence to suggest that practice with these tools can provide extra protection against the later development of post-traumatic stress and CF. ${ }^{[18,23]}$ This is due to the way the tools train the body to settle its biochemistry back down after intense, stressful or chaotic events. These exercises teach simple but powerful relaxation skills, including self-regulation through conscious breathing, word and phrase repetition, and progressive body relaxation. Participants also experienced guided imaging for deep relaxation. ${ }^{[23]}$

The intervention included training on living with intentionality and application for nurse residents, as well as the importance and methods of social connectedness and sharing of personal trauma narratives for mitigating professional stress. The nurse residents' explored self-care actions necessary for reenergizing, renewing, recharging which included: healthy diet, exercise, optimal sleep and stress mitigation strategies. ${ }^{[3,6,26]}$ Participants were provided seminar resources which included; guided imaging CD used in the seminar, seminar workbook and handouts. ${ }^{[23]}$

\subsection{Instrument}

The Professional Quality of Life Test (ProQOL) V5 ${ }^{[31]}$ was utilized to measure $\mathrm{CS}$ and $\mathrm{CF}$ at three time points, immediately before the intervention, at 2-month and 6-month after the intervention. The tool contains 30 self-reported items using a five point scale. The tool divides the questions into three subscales which characterize distinct although associated constructs: BO, STS and CS. ${ }^{[31]}$ The validity and reliability of the tool was previously reported as well as construct validity. For the subscales, the tool provides an alpha reliability of $0.84-0.90$ and a structural reliability coefficient of 0.91 . The scale is widely used to identify both the negative and positive effects of providing care. ${ }^{[31]}$ In addition, the nurse residents completed a questionnaire reporting which of the techniques taught in the intervention they used and how often they used it at two data points; 2-month and 6-month assessment. Qualitative data was also obtained as part of the nurse residency program.

\section{ReSUltS}

One hundred-seventy-six nurse residents returned the baseline questionnaires. At 2-month post-intervention, 96 questionnaires were matched with 94 considered eligible. At 6-months post-intervention, 37 questionnaires were returned and 34 were deemed eligible (36.2\% of eligible participants 
from 2-month follow-up). Nurse residents were predominantly female (85\%) and 20 to 30 years of age $(85 \%)$. Most had 1-3 years of health care experience $(77 \%)$ and most had a bachelor's degree as their highest educational attainment (97\%) (see Table 1).

Most nurse residents reported moderate STS at baseline (73\%), while most reported low burnout at 6-month postintervention. Significantly lower STS was observed at 6month post-intervention $(p<.001)$. At baseline, most nurse residents had moderate CS $(74 \%)$, with $27 \%$ reporting high CS. At 6-month post-intervention, CS rates were relatively similar, with $29 \%$ having high CS and $71 \%$ with moderate $\mathrm{CS}$. None had low CS at baseline or follow-up. Burnout rates were similar between baseline and post-interventions, with slightly lower burnout at 6-month post-intervention (50\% with low burnout at 6 month, compared to $47 \%$ at baseline) (see Tables 2 and 3 ).

The most frequently used techniques reported by the nurse residents were perceptual maturation/self-validation $(53 \%$ reporting daily use), followed by intentionality (50\%), connection and support (35\%), self-regulation (30\%), self-care and personal refueling (29\%). The nurse residents reported at least weekly implementation of self-care and personal refueling $(91 \%)$, social connection and support (85\%), inten- tionality (77\%), perceptual maturation/self-validation (74\%), and self-regulation (71\%) (see Table 4).

Table 1. Nurse resident demographics

\begin{tabular}{lll}
\hline Demographics $(\boldsymbol{n}=\mathbf{3 4})$ & Category & $\boldsymbol{n} \mathbf{( \% )}$ \\
\hline \multirow{4}{*}{ Age } & $20-25$ & $16(47 \%)$ \\
& $26-30$ & $13(38 \%)$ \\
& $31-35$ & $1(3 \%)$ \\
& $36-40$ & $2(6 \%)$ \\
& $41+$ & $2(6 \%)$ \\
Gender & Missing & $0(0 \%)$ \\
& Male & $5(15 \%)$ \\
& Female & $29(85 \%)$ \\
& Missing & $0(0 \%)$ \\
Years worked in Health Care* & $1-3$ & $26(77 \%)$ \\
& $4-7$ & $6(18 \%)$ \\
& $8-11$ & $1(3 \%)$ \\
& $12-15$ & $0(0 \%)$ \\
Years worked as RN & $16+$ & $1(3 \%)$ \\
& Missing & $0(0 \%)$ \\
& $1-3$ & $34(100 \%)$ \\
& Missing & $0(0 \%)$ \\
& Bachelor's & $33(97 \%)$ \\
& Master's & $1(3 \%)$ \\
& Missing & $0(0 \%)$ \\
\hline
\end{tabular}

*Some nurse residents may have worked in healthcare previously as technicians or nursing assistants

Table 2. Nurse resident prevalence of compassion satisfaction, burnout and secondary traumatic stress-baseline, 2-month and 6-month post-intervention

\begin{tabular}{lllll}
\hline $\mathbf{( N = 3 4 )}$ & & $\begin{array}{l}\text { Pre-intervention } \\
\mathbf{n}(\%)\end{array}$ & $\begin{array}{l}\text { 2 months } \\
\text { post-intervention** n (\%) }\end{array}$ & $\begin{array}{l}\mathbf{6} \text { months } \\
\text { post-intervention n (\%) }\end{array}$ \\
\hline & High* & $9(27 \%)$ & $11(38 \%)$ & $10(29 \%)$ \\
Compassion Satisfaction (CS) & Moderate & $25(74 \%)$ & $18(62 \%)$ & $0(0 \%)$ \\
& Low & $0(0 \%)$ & $0(0 \%)$ & $0(0 \%)$ \\
& Missing & $0(0 \%)$ & $5(15 \%)$ & $17(50 \%)$ \\
& Low* & $16(47 \%)$ & $20(69 \%)$ & $17(50 \%)$ \\
Burnout (BO) & Moderate & $18(53 \%)$ & $9(31 \%)$ & $0(0 \%)$ \\
& High & $0(0 \%)$ & $0(0 \%)$ & $0(0 \%)$ \\
& Missing & $0(0 \%)$ & $5(15 \%)$ & $21(62 \%)$ \\
& Low* & $9(27 \%)$ & $16(55 \%)$ & $13(38 \%)$ \\
Secondary Traumatic Stress (STS) & Moderate & $25(73 \%)$ & $13(45 \%)$ & $0(0 \%)$ \\
& High & $0(0 \%)$ & $0(0 \%)$ & $0(0 \%)$ \\
\hline
\end{tabular}

*Denotes optimal score for each subscale. ${ }^{* *}$ Results from 2 months post intervention are reported only for residents who completed the 6-month follow-up.

\section{Discussion}

Findings from this longitudinal study indicate that nurse resident CF resiliency education may be helpful. Estimates of nurse turnover in the U.S. typically approach $20 \%$; yet higher rates are reported in specific groups, such as new graduate nurses. ${ }^{[37-39]}$ Initial evidence suggests that the nurses from the millennial generation are more willing to leave their jobs, and may be more vulnerable to poor work environments, early career burnout, and may leave nursing. ${ }^{[37,39,40]}$ 
Table 3. Nurse resident pre-post compassion satisfaction, burnout and secondary traumatic stress scores

\begin{tabular}{|c|c|c|c|c|}
\hline Prevalence $(\mathrm{N}=34)$ & & Pre-intervention & $\begin{array}{l}6 \text { months } \\
\text { Post-intervention }\end{array}$ & $\begin{array}{l}p \text {-value (baseline } \\
\text { and } 6 \text { months) }\end{array}$ \\
\hline \multirow{3}{*}{ Compassion Satisfaction (CS) } & Mean (s.d.) & $38.6(5.8)$ & $39.4(5.2)$ & \multirow{3}{*}{ NS (.15) } \\
\hline & Median & 38.5 & 38.5 & \\
\hline & Range & $26-50$ & $30-50$ & \\
\hline \multirow{3}{*}{ Burnout (BO) } & Mean (s.d.) & $22.3(5.3)$ & $22.0(4.6)$ & \multirow{3}{*}{ NS (.69) } \\
\hline & Median & 23 & 22.5 & \\
\hline & Range & $13-35$ & $12-30$ & \\
\hline \multirow{3}{*}{ Secondary Traumatic Stress (STS) } & Mean (s.d.) & $25.5(6.7)$ & $21.2(4.7)$ & \multirow{3}{*}{$p<.001$} \\
\hline & Median & 26 & 21 & \\
\hline & Range & $11-36$ & $13-31$ & \\
\hline
\end{tabular}

Table 4. Nurse resident use of resiliency techniques taught in intervention (Frequency in descending order of daily use)

\begin{tabular}{llllll}
\hline $\begin{array}{l}\text { Frequency of Use at } 6 \text { months } \\
\text { (N = 34) }\end{array}$ & $\begin{array}{l}\text { Daily (1 time or } \\
\text { more) }\end{array}$ & Weekly & Monthly & Never & Missing \\
\hline Perceptual Maturation \& Self-Validation & $18(53 \%)$ & $7(21 \%)$ & $6(17 \%)$ & $3(9 \%)$ & $0(0 \%)$ \\
Intentionality & $17(50 \%)$ & $9(27 \%)$ & $4(12 \%)$ & $4(11 \%)$ & $0(0 \%)$ \\
Social Connectedness \& Support & $12(35 \%)$ & $17(50 \%)$ & $5(15 \%)$ & $0(0 \%)$ & $0(0 \%)$ \\
Self-regulation & $10(30 \%)$ & $14(41 \%)$ & $6(18 \%)$ & $4(11 \%)$ & $0(0 \%)$ \\
Self-Care \& Refueling & $10(29 \%)$ & $21(62 \%)$ & $1(3 \%)$ & $2(6 \%)$ & $0(0 \%)$ \\
Guided Imagery & $0(0 \%)$ & $3(9 \%)$ & $8(23 \%)$ & $23(68 \%)$ & $0(0 \%)$ \\
\hline
\end{tabular}

In a 2016 National Healthcare Retention Report, the estimated rate of nurse turnover was $17.2 \% .^{[13]}$ The average cost of nurse turnover reported in that study was $\$ 37,000$ to $\$ 58,400$ per registered nurse $(\mathrm{RN})$. In other studies, estimates of total hospital costs reach nearly $\$ 90,000$ per nurse. ${ }^{[41]}$ Additional studies are needed to explore organizational impact of $\mathrm{CF}$ interventions related to nurse turnover and adverse events associated with burnout. Building a workplace culture of resiliency to help nurse residents manage workplace stressors and reduce the associated negative health effects is an important consideration for organizations. One of the tools shared in this intervention was sharing their trauma narrative, this technique has shown benefit in graduate nurses. ${ }^{[42]}$

The results of this study at 6-month post-intervention were consistent with findings at 2-month post-intervention published elsewhere. ${ }^{[1]}$ At both 2-month and 6-month postintervention, STS was statistically significant and lower at baseline $(p<.001)$ (see Table 3$)$. While changes in CS and BO were not significant, they were trending in a positive direction indicating that this intervention provides protective resiliency factors in nurse residents. There might be generational differences not measured in this study. The nurse residents in this study, most of which are members of the millennial generation seemed to prefer the faster selfregulation techniques; (i.e breathing techniques) over the

Published by Sciedu Press longer techniques taught (guided imaging for deep relaxation) (see Table 4). The potential improved well-being of nurse residents lends itself to explore the effects on patient care, patient outcomes and retention rates within organizations.

\section{Limitations}

The sample size is relatively small and comprised of nurse residents from only one organization. Additionally, a smaller proportion of participants completed 6-month follow-up compared to the previously published 2-month follow-up. It is important to note that there may be differences between those who completed the 2-month and 6-month post-intervention and those who did not. The authors also cannot exclude the possibility that some of the participants might have previously engaged in some of the components of the intervention prior to the study (i.e., self-regulation, meditation, guided imagery). Regardless, significant differences between STS at baseline held at both 2-month and 6-month post-intervention suggesting that the results have remained consistent at two longitudinal time points. Only using one measurement tool may be considered a limitation to this study. Additional studies are needed to determine types of interventions, ideal timing of training, and if the 2-month and 6-month results are an indication of long-term impact. 


\section{ACKNOWLedgements}

The authors would like to thank Kellar Elliott BA, for his contribution to the manuscript.

\section{CONFlicts OF INTEREST Disclosure}

\section{REFERENCES}

[1] Iacoboni M. Imitation, empathy, and mirror neurons. Annu Rev Psychol. 2009; 60: 653-70. PMid:18793090 https://doi.org/10.1 146/annurev.psych.60.110707.163604

[2] Flarity K, Rhodes WJ, Reckard P. Intervening to improve compassion fatigue resiliency in nurse residents. Journal of Nursing Education and Practice. 2016; 6(12): 99-104. https://doi.org/10.5430/ jnep.v6n12p99

[3] Flarity K, Gentry JE, Mesnikoff N. The effectiveness of an educational program on preventing and treating compassion fatigue in emergency nurses. Adv Emerg Nurs J. 2013; 35(3): 247-58. PMid:23899949 https://doi.org/10.1097/TME.0b013e3182 $9 \mathrm{~b} 726 \mathrm{f}$

[4] Garman AN, Corrigan PW, Morris S. Staff burnout and patient satisfaction: evidence of relationships at the care unit level. J Occup Health Psychol. 2002; 7(3): 235-41. https://doi .org/10.1037/ 1076-8998.7.3.235

[5] Perry B, et al. An exploration of the experience of compassion fatigue in clinical oncology nurses. Can Oncol Nurs J. 2011; 21(2): 91-105. https://doi.org/10.5737/1181912x2129197

[6] Potter P, Pion S, Gentry JE. Compassion fatigue resiliency training: the experience of facilitators. J Contin Educ Nurs. 2015; 46(2): 83-8. PMid:25522376 https://doi .org/10.3928/00220124-20151 217-03

[7] Sundin L, Hochwalder J, Lisspers J. A longitudinal examination of generic and occupational specific job demands, and work-related social support associated with burnout among nurses in Sweden. Work. 2011; 38(4): 389-400. PMid:21508528

[8] Vahey DC, et al. Nurse burnout and patient satisfaction. Med Care. 2004; 42(2 Suppl): II57-66.

[9] Hooper C, et al. Compassion satisfaction, burnout, and compassion fatigue among emergency nurses compared with nurses in other selected inpatient specialties. J Emerg Nurs. 2010; 36(5): 4207. PMid:20837210 https://doi.org/10.1016/j.jen.2009.1 1.027

[10] Van Camp J, Chappy S. The Effectiveness of Nurse Residency Programs on Retention: A Systematic Review. AORN J. 2017; 106(2): 128-144. PMid:28755665 https://doi.org/10.1016/ j.aorn. 2017.06.003

[11] Goode CJ, et al. Lessons learned from 10 years of research on a postbaccalaureate nurse residency program. J Nurs Adm. 2013; 43(2): 73-9. PMid:23314789 https : //doi .org/10.1097/NNA .0b013e $31827 f 205 c$

[12] Li A, et al. Group cohesion and organizational commitment: protective factors for nurse residents' job satisfaction, compassion fatigue, compassion satisfaction, and burnout. J Prof Nurs. 2014; 30(1): 8999.

[13] Colosi B. national healthcare retention and RN staffing report. Nursing Solutions, Inc.

[14] Association AH. Resilience in the workplace. An evidence review and implications for practice. 2017.

[15] Accreditation C. Entry to Practice Residency Standards 2015. 2017. Available from: http://www.aacn.nche.edu/ccne-accredi
tation/CCNE-Entry-to-Practice-Residency-Standards -2015.pdf

[16] Figley CR, Kleber RJ. Beyond the "victim", in Beyond trauma. Springer. 1995.

[17] Gentry JE. Compassion fatigue: A crucible of transformation. Journal of Trauma Practice. 2002; 1(3-4): 37-61. https ://doi.org/ 10.1300/J189v01n03_03

[18] Gentry JE. Forward-Facing Trauma Therapy: Healing the Moral Wound. 2016, Sarasota, FL: Compassion Unlimited.

[19] Hunsaker S, et al. Factors that influence the development of compassion fatigue, burnout, and compassion satisfaction in emergency department nurses. J Nurs Scholarsh. 2015; 47(2): 186-94.

[20] Gentry JE, Baranowsky AB, Dunning K. ARP: The accelerated recovery program (ARP) for compassion fatigue. Treating Compassion Fatigue. 2002.

[21] Huggard P. Compassion fatigue: how much can I give? Med Educ. 2003; 37(2): 163-4. PMid:12558888 https://doi.org/10.104 $6 / j .1365-2923.2003 .01414 . x$

[22] Laposa JM, Alden LE, Fullerton LM. Work stress and posttraumatic stress disorder in ED nurses/personnel. J Emerg Nurs. 2003; 29(1): 23-8. https://doi.org/10.1067/men.2003.7

[23] Naparstek B. Guided Meditation Guided Imagery and VisualizationHealth Journeys. 2016. Available from: http://www.healthjour neys.com/

[24] Radey M, Figley CR. The social psychology of compassion. Clinical Social Work Journal. 2007; 35(3): 207-214. https ://doi .org/10 $.1007 / \mathrm{s} 10615-007-0087-3$

[25] Gillespie GL, Gates DM, Succop P. Psychometrics of the healthcare productivity survey. Advanced Emergency Nursing Journal. 2010; 32(3): 258-271. https://doi.org/10.1097/TME.0b013e3181 e97510

[26] Flarity K, et al. Intervening to Improve Compassion Fatigue Resiliency in Forensic Nurses. Adv Emerg Nurs J. 2016; 38(2): 147-56. PMid:27139136 https://doi.org/10.1097/TME. 0000000000 000101

[27] Gentry JE, Baggerly J, Baranowsky A. Training-as-treatment: effectiveness of the Certified Compassion Fatigue Specialist Training. Int J Emerg Ment Health. 2004; 6(3): 147-55. PMid:15481476

[28] El-Bar N, et al. Compassion fatigue, burnout and compassion satisfaction among family physicians in the Negev area - a cross-sectional study. Isr J Health Policy Res. 2013; 2(1): 31.

[29] Mathur MB, et al. Perceived stress and telomere length: A systematic review, meta-analysis, and methodologic considerations for advancing the field. Brain Behav Immun. 2016; 54: 158-169.

[30] Thimmapuram J, et al. Effect of heartfulness meditation on burnout, emotional wellness, and telomere length in health care professionals. J Community Hosp Intern Med Perspect. 2017; 7(1): 2127. PMid:28634520 https://doi.org/10.1080/20009666.201 6.1270806

[31] Stamm B. The ProQOL (Professional quality of life scale: Compassion satisfaction and compassion fatigue). Pocatello, ID: ProQOL. org. Retrieved August. 2010. 19: 2011. 
[32] Slatten LA, David Carson K, Carson PP. Compassion fatigue and burnout: what managers should know. Health Care Manag (Frederick). 2011; 30(4): 325-33. PMid:22042140 https : //doi .org/10 .1097/HCM. Ob013e31823511f7

[33] Greene RR, Galambos C, Lee Y. Resilience theory: Theoretical and professional conceptualizations. Journal of Human Behavior in the Social Environment. 2004; 8(4): 75-91. https ://doi.org/10.1 300/J137v08n04_05

[34] Sabo BM. Compassion fatigue and nursing work: can we accurately capture the consequences of caring work? Int J Nurs Pract. 2006; 12(3): 136-42. PMid:16674780 https://doi.org/10.111 $1 / \mathrm{j} .1440-172 \mathrm{X} .2006 .00562 \cdot \mathrm{x}$

[35] MacKusick CI, Minick P. Why are nurses leaving? Findings from an initial qualitative study on nursing attrition. Medsurg Nurs. 2010; 19(6): 335-40. PMid:21337990

[36] Potter P, Deshields T, Rodriguez S. Developing a systemic program for compassion fatigue. Nurs Adm Q. 2013; 37(4): 326-32. PMid:24022286 https://doi.org/10.1097/NAQ.0b013e3182 a2f $9 \mathrm{dd}$
[37] Hayes LJ, et al. Nurse turnover: a literature review - an update. Int J Nurs Stud. 2012; 49(7): 887-905. PMid:22019402 https: //doi.org/10.1016/j.ijnurstu.2011.10.001

[38] Kovner CT, Djukic M. The nursing career process from application through the first 2 years of employment. J Prof Nurs. 2009; 25(4): 197-203. PMid:19616187 https://doi.org/10.1016/j. profnurs.2009.05.002

[39] Rudman A, et al. Monitoring the newly qualified nurses in Sweden: the Longitudinal Analysis of Nursing Education (LANE) study. Hum Resour Health. 2010; 8: 10.

[40] Kovner CT, et al. What does nurse turnover rate mean and what is the rate? Policy Polit Nurs Pract. 2014; 15(3-4): 64-71.

[41] Jones CB. Revisiting nurse turnover costs: adjusting for inflation. J Nurs Adm. 2008; 38(1): 8-11. PMid:18157000 https://doi.org/ 10.1097/01. NNA.0000295636.03216.6f

[42] Bolden $\mathrm{L}$, et al. The use of reflective practice in new graduate registered nurses residency program. Nurs Adm Q. 2011; 35(2): 134-9. PMid:21403487 https://doi.org/10.1097/NAQ.0b013e3182 Ofeb5e 